of traction forward by the left hand upon the vertex, but it seems to me that its value as a means of getting the head forwards is almost nil, until the danger point of a ruptured perineum is practically past; granting that it is of any value, it must tend to promote premature extension, which is the very thing we want to avoid. When the head is distending the perineum, and the point of greatest tension of the fore head thereon is reached, the occiput is firmly fixed behind the pubic arch, and no amount of traction forwards will relieve the tension on the perineum at that stage. The occiput cannot, in other words, be pulled forwards withou causing the forehead to rotate forwards, thus increasing the strain upon the perineum. Besides, even if we allow that traction forwards is of any value at that time, I do not think it reasonable to suppose that any appreciable amount of force can be exerted by mere pressure forwards, and that too at a great mechanical disadvantage upon such a thing as an extremely slippery vertex.

(b) This method, whereby the perineum is safeguarded by pressure of the concavity between the thumb and first finger of the right hand, seems to me to break down because, at the part of the perineum where most support is required, the point where normally would be situated the junction of the two labia majora behind, least support can be given. The two lateral parts are undoubtedly supported by the thumb and forefinger, but, at the apex of the concavity between the latter, little if any support can, I hold, be given, and it is just here where lacerations commence, and therefore most support is required. The apex of the concavity between the thumb and forefinger is quite soft, and can exert scarcely any lateral pull towards the middle line of the perineum. In addition to this, the parts are usually very slippery, and do not admit of much prehension.

(c) Any push forwards, either per anum or by pressure behind it, is largely negatived by the fact that the occiput is more or less fixed behind the pubic arch, just at the time when there is most danger of perineal rupture, and, therefore, any attempt to push forward is futile. In fact, any pressure from behind forwards seems to me to have the effect, not of pushing the head forwards, but of producing a small amount of rotation of the head round an axis through the points where the occipital or parietal bones, as the case may be, impinge on the pubic arch. After the occiput has passed these points, pressure from behind forwards will certainly drive the head forwards, but, as I have already observed, the danger point of rupture has then passed.

(d) Too little attention seems to me to be paid to delivery of the shoulders in preventing laceration of the perineum, as a large proportion of ruptures is caused, not by delivery of the head, but by faulty delivery of the shoulders.

I shall now venture to give a short outline of a method which I have employed in a large number of cases with very satisfactory results.

When the fetal head is moderately distending the perineum, the latter and the parts adjacent are thoroughly dried with a hot sterilized towel ; all moisture must be wiped off. At the moment when the tension on the perineum is approaching its maximum - this can be determined easily with a little experience-the left hand of the accoucheur is employed in pressing slightly upon the vertex to prevent any premature or sudden expulsion of the head; there is no necessity for passing the arm between the thighs of the mother. The right hand then grasps the perineum in the manner alluded to in $(b)$, but with this important difference : that between it and the perineum is interposed a hot sterilized towel-the small rough sanitary towelettes are excellent for the purpose-in such a way that the edge of the concavity between the thumb and index finger, the edge of the towel, and the lip of the perineum are just in line with each other, a double fold of the towel to fit into the apex of the concavity having previously been made, to supply the deficiency alluded to at that point. Firm pressure is then exerted at every pain, through the bitemporal diameter of the fetal head, if there appear to be any undue stretching or tendency to laceration. No attempt is made to push the head forwards until the occiput ceases to engage behind the pubic arch. By these manœuvres three purposes are sprved :

I. By firm pressure through the bitemporal diameter premature extension of the head is prevented, without retarding its progress.

2. By means of the drying of the parts and the hot towel a much firmer grip, and consequently much greater support, of the perineum can be obtained than could possibly be produced by the bare hand on a gurface which is usually very slippery.
3. Uniform pressure is obtained on all parts of the perineum, and the part where there is most stretching receives its due measure of support.

On the head being delivered, and when restitution has taken place the shoulders are lying in the anterior posterior diameter of the outlet, and their delivery again endangers the perineum to a much greater extent, I think, than is usually supposed, chiefly due to the prevailing practice, as recommended in textbooks, of allowing the posterior shoulder to be born first. If, now, after the head is born we exercise gentle traction backwards, the next pain will usnally cause the anterior shoulder to free itself from its position behind the pubic arch, while the perineum lies over the posterior shoulder and is subjected to only a moderate degree of tension, and if the outlet is narrow the anterior arm can usually be extracted with very little difficulty after the anterior shoulder is born, thus substituting a much smaller diameter of the child. If we allow the posterior shoulder to be born first, the anterior shoulder remains firmly fixed behind the pubic arch, while the posterior shoulder sweeps over the perineum and stretches it again to its utmost limit. No "guarding" can be carried out at this point, because if any pressure backwards on the shoulders be fxerted, the progress of the child is seriously retarded.

I put forward this brief outline of my modified method with a considerable amount of diffidence, knowing that it is at direct variance with gome of the textbook canons of the second stage of labour; but I can only say that since I have employed it in about 400 consecutive cases of labour I have found it singularly effectual, and I should be extremely interested to hear how it fares after trial by more practised hands than my own.

\section{A CASE OF QUADRUPLETS.}

By LLEWELLYN W. ROBER IS, M.B., Ch.B.Melb., M.R.C.S.ENG., L.R.C.P. LoND., Cowra, New Bouth Wales.

MrS. G., aged 32, of French extraction, married twelve years, with a family history of twins on her maternal side. gave \& personal history of six previous confinements, resulting in delivery of ten children in following sequence: Twins, triplets, a single child, then twins again, and two single children, all of whom are living except the triplets, which were premature (geven months). In addition, eighieen months ago, she had placenta praevia at five months with decomposing fetus, necessitating removal piecemeal under anaesthesia.

On May 22nd the patlent was examined, owing to slight escape of liquor amnii, and twins (at least) diagnosed, as two or more fetal heads could be felt in her enormonsly-distended abdomen, but no distinct fetal heart sounds could be made out owing to loud uterine souffle.

On May 26th, being then eight months pregnant, slight uterine contractions came on at 2 a.m., with only slight pain. The head of the first child-a boy-was found on perineum, and it was born within an hour. The membranes of the second child being ruptured a head was felt presenting, but it was delayed by the third child's feet at the brim, being impacted against the head of the second; this necessitated slight choloroform anaesthesia and introduction of the hand to push up the feet of the third child, and to bring down the second child's head into cavity of pelvis. The child-a boy -was easily and rapidly delivered by forceps about threequarters of an hour after the delivery of the first. The third -another boy-was easily sejzed by the feet and delivered five minutes later, but was stillborn and resisted all efforts at resuscitation. The pains now became much stronger, and after rupturing the membranes a fourth child-a girl-was born as a breech presentation a quarter of an hour aiter the third.

Until then there had been no haemorrhage whatever, but it now became very free, and although the huge flabby uterus contracted fairly well, simple expression was unsuccessful to expel the secundines, and the hand had to be introduced, and each of the four adherent placentas were manually removed separately, the haemorrhage being then controlled by a hot antiseptic douche. There were lour distinct and separate placentas about 5 to 6 in. square and four \&eparate bags of membranes, although the second and third p'acentas were found united after removal by a band of memt rave Eome 4 in. or more wide. The patient had a slight elevation of temperature on the second and third days, which intrauterine douching reduced; with this exception, mother and her three children 
(two boys and one girl, weighing each about 5 to $6 \mathrm{lb}$.) are now thriving.

Playfair quotes statistics showing that the relative frequency of the occurrence of quadruplets varies from 1 in over $2,000,000$ births in France to 1 in 185000 in Ireland.

\section{PRIMARY MALIGNANT GRUWTH OF LIVER. BX J. BRUCE-BAYS, M.D.LOND, Grahamstown.}

THE following case, the fourth of a series under my care, is of interest from the obscurity of the symptoms and the rapidity of the fatal termination.

Dassien, a Kaffir aged about 40 years had been engaged on Friday in unloading heavy goods from the train, and was then apparently in good health. On Saturday at midday he passed water, but on Sunday being unable to do so he sent for me. I found him lying in his hut complaining only of inability to micturate. There was no history of previous illness, nor of any injury. The abdomen, somewhat distended, was dull in the lower part on percussion. On passing a solt catheter a few drops only of urine flowed away. As the man was somewhat collapsed, though able to stand upright, I sent him into the Albany General Hospital, under my care, where he died soon after admission.

On making a pst-mortem examination the abdomen was found to contain a large amount of clot, the blood having apparently come from the liver, which was much enlarged, weighing $7 \mathrm{lb} .7 \mathrm{oz}$, about half of it consisting of new growth. All the other viscera were healthy, no trace of any tumour being found in any other organ. Dr. G. C. Purvis, who kindly examined the growth, described it as a multiple cylindrical cancer of the liver, and reported as follows:

"The individual tumours varied very much in size; the smallest was about the size of a pea and the lurgest that of a walnut. The tumours were scattered throughout the liver. The colour of each growth was almost white, the consistence that of cheese. Exch growth was surrounded by a white fibrous tissue capsule, and the liver cells in the immediate neighbourhood of the capsule much atrophied, and contained yellowish grains of pigment. The tumour itself was composed of irregularly-disposed tubules of columnar cells, and the lumen of the tubules contained some secretory substance of a homogeneous appearance, which stained of a greenish colour with methylene blue, and of a deep red tint with eosin. The stroma, which was apparently cımposed of ordlnary white fibrous tissue, was scanty, so that the tubules almost touched each other. Many of the nuclei of the cancer cells were undergoing mitotic changes.

Single Kidney: Ureter Passinf: to Opposite Side.-A singular anomaly has been reported by Horand ("Absence congénitale du rein droit, ure ère droit desservant le rein gauche." Bulletins et mém. de la Soc. Anat. de Paris. April, 905). In the necropsy on an infant born at the seventh month, which had died of athrepsia when under 4 months of age, he found that the right kidney was entirely wanting, nor was there any trace of a right renal artery or vein. The leit kidney was in normal position, hypertrophied and lobulated. The left renal vessels showed no anomaly. The pelvis of this single kidney passed into a ureter of large calibre, which ran downwards towards the right, passing in front of the left common iliac artery, much posterior to the left sacro-iliac synchrondosis, and sweeping round the inner wall of the bony pelvis on the right side internal to the vessels. Finally, it passed through the walls of the bladder, opening on the right side at the normal level of the right ureteral oritice. A left orifice was detected; it was prrmeable and passed into a rudicuentary left ureter. This canal ended in a thin filament at the point on the brim of the pelvis where the normal left ureter passes down vards; it was totally disconnected from the leit kidney. The left vesicula seminalis was absent, but the left vas, epididymis, and testis showed no abnormality. The left suprarenal capsule was well developed, the right was detected greatly atrophied and flattened against the right side of the vertebral column; it possessed a small capsular artery and vein. Horand observes that the surgeon might be badly puzzled in examining a patient with renal disease if an anomaly of this class existed. The cystoscope would show urine issuing from the right ureteral orifice, whilst the left, apparently normal, gave passage to none. The symptoms might justify nephrectomy, but in such a case the surgeon might remove the left kidney under the false impression that its fellow existed and was normal.
SEVENTY-THIRD ANNUAL MEERING

\section{OF THR \\ Britísh Alterical Assoriation.}

Held at Leicester, July 24th, 25th, 26th, 27th, and 28th, 1905.

PROCEEDINGS OF SECTIONS.

\section{SECTION OF STATE MEDICINE.}

Philip Boobryer, M.D., President.

\section{A DISCUSSION ON ISOLATION HOSPITALS.}

I.-Grorge Wilson, M.A., M.D., LL.D., F.R.S.E.,

Medical Officer of Health, Mid-Warwickshire Combined District.

In undertaking to open the discussion on this wide and now much vexed question of hospital isolation, I may explain at the outset that the facts and opinions which I have to lay before you are based on the experience gained in the eanitary supervision of a large combined district comprising three urban and seven rural districts during the long period of thirty-two years. I wish also to make it clear that, like a great many other enthusiasts in those early days, I held the strongest possible views concerning the value of hospital isolation, not so much for the benefit of the patient, or of the householder, or employer of labour, but for the benefit of the public at large, as a most important aid in controlling the spread of such dangerous infectious diseases as small-pox, scarlet fever, diphtheria, and enteric fever. I therefore commenced to urge the erection of isolation hospitals shortly after I was first appointed, but in order that they should not become too heavy a burden on the rates, I have all along advocated combination of districts to embrace as wide workable areas as possible, and by that I mean areas with an outside radius of about twelve miles from the hospital site. For half of the districts, and more than half of the population, such combinations were secured and hospitals erected for other diseases as well as for small-pox at a comparatively early date, but with respect to the other districts there were recurrent difficultit $s$ in inducing sanitary authorities to combine, and, failing combination we had to do the best we could: we had recourse to quarantine as much as possible, paying for nursing in severe cases, as well as other precautionary measures, and on the whole with very gratifying results. I for one, therefore, welcomed the passing of the Isolation Hospitals Act of 1893 . This Act ought to have greatly facilitated the combination of large hospital districts in administrative counties, but, unfortunately, small boroughs of 5,000 or 10,000 inhabitants were exempted from the operation of the Act unless with consent, and that is generally by no means easy to secure. Then, too, another difficulty has arisen with regard to the new rural districts embraced in unions extending into adj acent counties which were created by the Local Government Act of 1894 . It turns out that adjacent county councils have no powtr to issue a joint order to embrace the $s$ parate districts in any such overlapping union, even when the district councils concerned have agreed to combine. As an instance in point, I may mention that such an order was issued nearly two years ago by the Warwickshire and Northamptonshire County Councils, combining three districts, including the town of Rugby, and also an adjoining rural district, after a full legal agreement had been entered into by the district councils concerned, but the order was found to be ultra vires. It therefore devolved upon the Local Government Board to hold a separate inquiry, and a Provisional Order has at last been obtained.

I refer to this phase of the subject in passing because I hold that until larger powers are conceded to the Local Government Board and county councils to include in a county any borough, whether small or large, in a hospital district, to rearrange such districts, and to issue joint orders so as to include districts in adjoining counties, it would be a sheer waste of money for small urban or rural distriets to provide properly-equipped hospitals for their own separate and sole use. I think, too, that districts without hospital accommodation situated in the neighbourhoed of county 